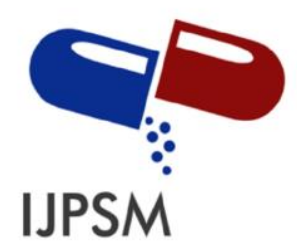

Miming Andika et al, International Journal of Pharmaceutical Sciences and Medicine (IJPSM),

Vol.7 Issue. 2, February- 2022, pg. 1-6

ISSN: 2519-9889

Impact Factor: 5.721

\title{
Effects of Bisoprolol on Decreased Blood Pressure of Systole in Male White Rats Hypertension and Hypertension with Complications of Liver Dysfunction
}

\author{
Miming Andika ${ }^{1}$; Vilma Humaira ${ }^{2}$; Relin Yesika ${ }^{3}$ \\ ${ }^{1}$ Fort De Kock University, Mimingandika@fdk.ac.id \\ ${ }^{2}$ Sumatera Barat University, Vilmahumaira56@gmail.com \\ ${ }^{3}$ Baiturrahmah University, Relinyess11@gmail.com \\ DOI: 10.47760/ijpsm.2022.v07i02.001
}

\begin{abstract}
Hypertension is a major public health problem and is known as an independent risk factor for cardiovascular disease. Patients with hypertension often experience complications such as liver dysfunction. Antihypertensive beta-blockers are often used by the public to treat high blood pressure and excessive heart rate. This study aimed to examine the effect of bisoprolol on decreasing systolic and diastolic blood pressure in hypertensive and hypertensive male white rats with complications of liver dysfunction. In this study, all-male white rats were made hypertensive by being induced with $\mathrm{NaCl}$. Then, the group of animals complicated by liver dysfunction was induced with $\mathrm{CCl} 4$, then measured using a v5 ${ }^{+} 5010$ photometers. Meanwhile, the systolic blood pressures were measured using a CODA (kent scientific) instruments blood pressure gauge (Noninvasive blood pressure). The data from this study were analyzed by two-way ANOVA. It was found that the administration of bisoprolol at a dose of $2.5 \mathrm{mg}, 5 \mathrm{mg}$, and $10 \mathrm{mg}$ significantly decreased systolic blood pressure $(\mathrm{p}=0.05)$. And the most effective dose is $10 \mathrm{mg}$ in lowering systolic blood pressure in hypertensive and hypertensive male white rats with complications of liver dysfunction.
\end{abstract}

Keywords: Hypertension, Liver dysfunction, Systole, Bisoprolol.

\section{Introduction}

Hypertension is also known as high blood pressure (HBP), is a long-term medical condition in which the blood pressure in the arteries is persistently elevated. Patients with Diastolic Blood Pressure (DBP) < $90 \mathrm{~mm}$ $\mathrm{Hg}$ and Systolic Blood Pressure (SBP) $\geq 140 \mathrm{~mm} \mathrm{Hg}$ have isolated systolic hypertension ${ }^{[1]}$. Hypertensive patients experience an increase in systolic blood pressure of $140 \mathrm{~mm} \mathrm{Hg}$ and a diastolic pressure of $90 \mathrm{~mm} \mathrm{Hg}$ or more, the complications that occur in hypertension are the result of a continuous increase in blood pressure, with consequent changes in blood vessels and heart, or because of the atherosclerotic process exacerbated by hypertension ${ }^{[2]}$. Patients with hypertension will take medicine, while drug metabolism mostly occurs in the endoplasmic reticulum of liver cells. If a person has a liver failure or the liver cannot carry out various metabolic processes, it can disrupt the blood flow rate and trigger an increase in heart work so that hypertension occurs ${ }^{[3]}$. 


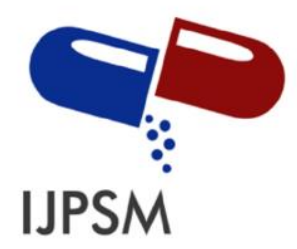

Miming Andika et al, International Journal of Pharmaceutical Sciences and Medicine (IJPSM), Vol.7 Issue. 2, February- 2022, pg. 1-6

ISSN: 2519-9889

Impact Factor: 5.721

Currently, beta-blockers are recommended as the mainstay of therapy in hypertensive patients in the setting of comorbidities, such as coronary artery disease and heart failure; these therapies target a lower heart rate and decreased myocardial oxygen demand, in addition to lowering blood pressure ${ }^{[4]}$. Beta-blockers are used to block beta-adrenergic receptors, resulting in a slower heartbeat so that it can reduce heart rate and oxygen consumption so that blood pressure becomes normal ${ }^{[5]}$.

There are only three beta-blockers used in the treatment of hypertension and heart failure, they are carvedilol, metoprolol succinate, and bisoprolol ${ }^{[6] .}$ Bisoprolol is the most widely used of the three betablockers. Compared with atenolol, bisoprolol has a better effect on central blood pressure management ${ }^{[7]}$. Bisoprolol is a second-generation beta-blocker that selectively antagonizes 1- receptor (cardioselective). Based on a study conducted by Taniguchi et al in 2013 about switching from carvedilol to bisoprolol in improving the side effect state in hypertensive patients with dizziness ${ }^{\left[{ }^{[8]}\right.}$. Bisoprolol is useful in the treatment of hypertension in the presence of changes in heart rhythm and changes in blood vessels ${ }^{[9]}$. Other studies have shown that propranolol and bisoprolol can decrease heart rate even at rest ${ }^{[10]}$.

Based on the explanation above and there is no research on the many effects of disease pathologies such as liver dysfunction in people with hypertension that irregularly work the heart to pump blood, then researchers are interested in researching the effects of bisoprolol on decreased blood pressure systolic and diastolic in white mice male hypertension and hypertensive with complications of liver dysfunction. But in this journal the research will show about effects of bisoprolol on decreased systolic blood pressure in white mice male, whereas diastolic blood pressure will publish later.

\section{Materials and Methods}

\subsection{Equipment}

The equipment used includes the usual stuff in pharmacology laboratories. The instruments used include Analytical Scale (Precisa), Photometer 5010V5+, and CODA Non-Invasive Blood Pressure (Kent Scientific Corporation), Triple Beam Balance (OHAUS), UV-Vis spectrophotometer (Shimadzu), Animal cages, Beaker glass, Syringe, Oral needle, Mortar, and Stamper.

\subsection{Materials}

The materials used in this study are Bisoprolol (Kimia Farma), CCl4 (Sigma), SGPT-SGOT kit reagent (DiaSys) Sodium Chloride (Merck), Distilled Water (PT. Brataco), Sodium Carboxymethyl Cellulose (Na CMC) (PT. Brataco), Hi-Pro-Vite 511 pellet chicken feed (PT. Charoen Indonesia).

\subsection{Procedure}

\subsubsection{Sample preparation}

The sample used for this study was bisoprolol with varying doses of $2.5 \mathrm{mg}, 5 \mathrm{mg}$ dan $10 \mathrm{mg}$.

\subsubsection{Preparation of experimental animals}

The experimental animals used were 60 white male rats aged 2-3 months with a 200-250 grams body weight. Before being treated, the rats were acclimatized for one week to adapt to their environment. Eating and drinking during maintenance are given sufficiently, animals are weighed, and their behavior observed. The mice used for the experiment were considered healthy; that is, during maintenance, the bodyweight of rats did not decrease more than $10 \%$ and visually showed normal behavior ${ }^{[11]}$.

\subsubsection{Preparation of 0.5\% Na CMC Suspension}

Sprinkle $500 \mathrm{mg}$ of sodium carboxymethyl cellulose in $10 \mathrm{~mL}$ of hot water in a hot mortar, leave for 15 minutes, then grind until homogeneous and dilute with distilled water to a volume of $100 \mathrm{~mL} 0.5 \% \mathrm{Na} \mathrm{CMC}$ suspension used to dilute bisoprolol ( $2.5 \mathrm{mg}, 5 \mathrm{mg}$ dan $10 \mathrm{mg}$ ). 


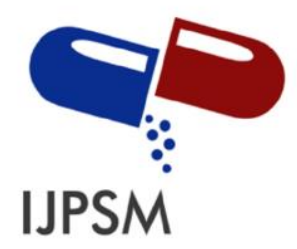

Miming Andika et al, International Journal of Pharmaceutical Sciences and Medicine (IJPSM), Vol.7 Issue. 2, February- 2022, pg. 1-6

ISSN: 2519-9889

Impact Factor: 5.721

\subsubsection{Preparation of $8 \%$ sodium chloride solution}

$8 \mathrm{~g} \mathrm{NaCl}$ is dissolved in $100 \mathrm{~mL}$ of distilled water. $\mathrm{NaCl}$ solution is given to mice every day for three weeks orally ${ }^{[12]}$.

\subsubsection{Preparation of CCl4 solution}

CCl4 solution is made with a concentration of $0.05 \mathrm{ml} / \mathrm{kg}$ Body wight with olive oil solvent ${ }^{[13]}$.

\subsubsection{Gave bisoprolol to test animals}

The experimental animals were divided into 2 groups, namely the hypertension rat group and hypertension with complications of liver dysfunction rat group. The hypertensive rat group and hypertension with complications of liver dysfunction rat group, each had 5 groups, where each group was given different treatment including Group 1: rats were not made hypertensive and were not given bisoprolol. Group 2: rats made hypertension and were not given bisoprolol. Group 3: rats were made hypertensive and given bisoprolol $2.5 \mathrm{mg}$ dose. Group 4: rats made hypertension and were given a bisoprolol dose of $5 \mathrm{mg}$. Group 5: rats made hypertension and were given a bisoprolol dose of $10 \mathrm{mg}$. Rats were made hypertensive by giving $8 \%$ $\mathrm{NaCl}$. Hypertension with complications of liver dysfunction rat group was given the same treatment as the hypertensive animal group, but hypertension with complications of liver dysfunction rat group was given $\mathrm{CCl} 4$ before being given bisoprolol. CCl4 to increase SGPT levels.

\subsubsection{Blood pressure measurement}

Measured the blood pressure of white mice were using a noninvasive method with the Adinstrument NIBP (CODA) tool, measurements were taken in a room with room temperature. The tool used connects to the CODA application and the application is enabled to start the experiment. Before the blood pressure measurement, the Adinstrument NIBP device that has been connected to the computer is calibrated first. After that, the mice are inserted in a cylindrical tube (shell) with the tail part out, the cover is installed to prevent the rat from moving freely during testing. The cylinder is then placed on a heating plate, then the occlusion cuff and VPR are mounted on the tail of the mouse and left for 10 minutes to adapt. Blood pressure measurement measures systolic blood pressure. Rats were considered hypertensive when the blood pressure was 140/90 $\mathrm{mmHg}{ }^{[14]}$

\subsubsection{SGPT levels measurement}

SGPT levels were measured using clinical photometer UV spectrophotometry 5010 5+. Measurement of SGPT levels on the 6th day.

\section{Results and Discussion}

The results of observations of the decrease in systolic blood pressure in male white rats in the hypertensive animal group and the hypertensive animal group with complications of liver dysfunction were the average data for the hypertensive animal group, systolic blood pressure without medication $=151.08 \mathrm{mmHg}$, dose $2.5 \mathrm{mg}=$ $145.48 \mathrm{mmHg}$, a dose of $5 \mathrm{mg}=144.17 \mathrm{mmHg}$, and a dose of $10 \mathrm{mg}=141.22 \mathrm{mmHg}$. The results of the examination of systolic blood pressure in male white rats can be seen in table 1 and figure 1 . In the results of the two-way ANOVA test, it is known that the sig value of systolic blood pressure with a value (sig $0.00<0.05$ ), means there is a difference in the mean decrease in systolic blood pressure between positive controls and variations in bisoprolol doses in the hypertension group. So, it can be concluded that bisoprolol dosage variations significantly affected the decrease in systolic blood pressure of male white rats in the hypertension group.

The results of the observation of a decrease in systolic blood pressure in the hypertensive-liver dysfunction group of animal's systolic blood pressure without medication $=152.43 \mathrm{mmHg}, 2.5 \mathrm{mg}$ dose $=150.24 \mathrm{mmHg}, 5$ $\mathrm{mg}$ dose $=148.61 \mathrm{mmHg}$, and $10 \mathrm{mg}$ dose $=147.29 \mathrm{mmHg}$. The results of the examination of systolic blood pressure in male white rats in the hypertension-liver dysfunction group can be seen in Table 2 and Figure 2. 


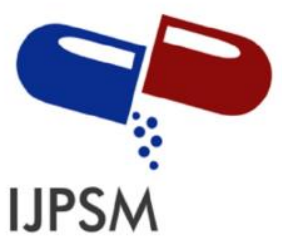

Miming Andika et al, International Journal of Pharmaceutical Sciences and Medicine (IJPSM), Vol.7 Issue. 2, February- 2022, pg. 1-6

ISSN: 2519-9889

Impact Factor: 5.721

In the results of the two-way ANOVA test, it is known that the sig value of systolic blood pressure is (sig $0.00<0.05$ ), which means that there is a difference in the mean decrease in systolic blood pressure between the positive controls and the dose variation of bisoprolol in the hypertension-liver dysfunction group. So, it can be concluded that bisoprolol dose variation significantly affected the decrease in systolic blood pressure of male white rats in the hypertension-liver dysfunction group.

Table 1. The average effect of variations in bisoprolol dose and time on the reduction of systolic blood pressure in hypertensive conditions.

\begin{tabular}{|c|c|c|c|c|c|}
\hline \multirow{2}{*}{ Group } & \multicolumn{4}{|c|}{ Time (hour) } & \multirow{2}{*}{$\begin{array}{l}\text { Average } \\
\text { (mmHg) }\end{array}$} \\
\hline & 0 & 1 & 2 & 3 & \\
\hline Dose $0 \mathrm{mg}$ & $149.48 \pm 0.78$ & $150.42 \pm 1.76$ & $150.64 \pm 1.44$ & $153.78 \pm 2.59$ & $151.08 \pm 1.87^{d}$ \\
\hline Dose $2.5 \mathrm{mg}$ & $150.42 \pm 1.76$ & $148.40 \pm 2.01$ & $143.12 \pm 1.12$ & $139.98 \pm 1.30$ & $145.48 \pm 0.41^{c}$ \\
\hline Dose $5 \mathrm{mg}$ & $150.64 \pm 1.44$ & $147.79 \pm 1.34$ & $141.62 \pm 1.19$ & $136.65 \pm 1.38$ & $144.17 \pm 6.27^{b}$ \\
\hline Dose $10 \mathrm{mg}$ & $149.48 \pm 0.78$ & $145.70 \pm 0.84$ & $137.80 \pm 2.11$ & $131.92 \pm 2.25$ & $141.22 \pm 7.88^{a}$ \\
\hline $\begin{array}{l}\text { Average } \\
\text { (mmHg) }\end{array}$ & $150 \pm 0.61^{s}$ & $148.08 \pm 1.94^{r}$ & $143.29 \pm 5.38^{q}$ & $140.58 \pm 9.40^{p}$ & \\
\hline
\end{tabular}

Note: ${ }^{\mathrm{a}, \mathrm{b}, \mathrm{c}, \mathrm{d}, \mathrm{e}, \mathrm{f}, \mathrm{g}}$ are different superscripts in the same column, ${ }^{\mathrm{p}, \mathrm{q}, \mathrm{r}, \mathrm{s}}$ different superscripts on the same line.

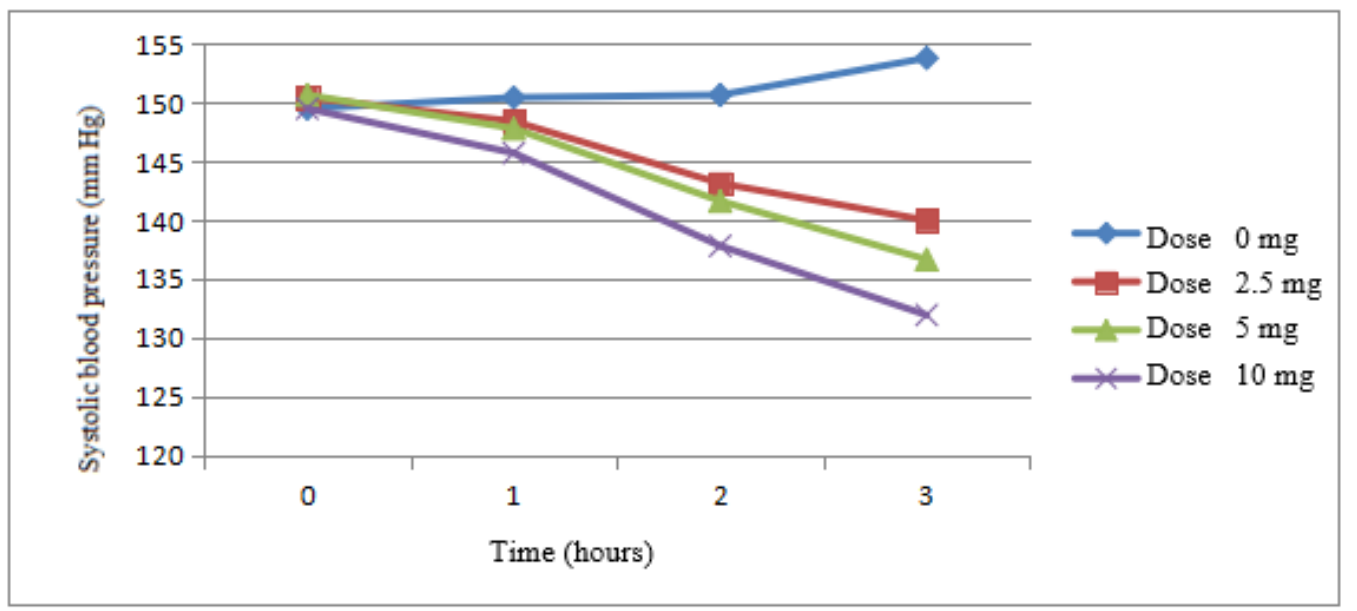

Figure 1. Graph of average systolic blood pressure in hypertension conditions at hours 0, 1, 2 and 3

Table 2. The average effect of variations in bisoprolol dosage and time of decreasing systolic blood pressure in conditions of hypertension-liver dysfunction

\begin{tabular}{|c|c|c|c|c|c|}
\hline \multirow{2}{*}{ Group } & \multicolumn{4}{|c|}{ Time (hour) } & \multirow{2}{*}{ Average (mmHg) } \\
\hline & 0 & 1 & 2 & 3 & \\
\hline Dose $0 \mathrm{mg}$ & $150.42 \pm 1.76$ & $151.96 \pm 2.39$ & $153.56 \pm 2.16$ & $153.78 \pm 2.59$ & $152.43 \pm 1.57^{\mathrm{c}}$ \\
\hline Dose $2.5 \mathrm{mg}$ & $153.56 \pm 2.16$ & $152.26 \pm 1.86$ & $149.06 \pm 2.07$ & $146.10 \pm 1.86$ & $150.24 \pm 3.35^{b}$ \\
\hline Dose $5 \mathrm{mg}$ & $151.96 \pm 2.39$ & $150.46 \pm 2.06$ & $147.73 \pm 1.35$ & $144.28 \pm 1.28$ & $148.61 \pm 3.37^{\mathrm{a}}$ \\
\hline Dose $10 \mathrm{mg}$ & $153.78 \pm 2.59$ & $150.26 \pm 2.14$ & $145.08 \pm 2.3$ & $140.05 \pm 2.17$ & $147.29 \pm 6.01^{\mathrm{a}}$ \\
\hline $\begin{array}{l}\text { Average } \\
\text { (mmHg) }\end{array}$ & $152.43 \pm 1.57^{\mathrm{r}}$ & $151.23 \pm 1.02^{r}$ & $148.86 \pm 3.54^{q}$ & $146.05 \pm 5.74^{p}$ & \\
\hline
\end{tabular}

Note: ${ }^{\mathrm{a}, \mathrm{b}, \mathrm{c}, \mathrm{d}, \mathrm{e}, \mathrm{f}, \mathrm{g}}$ are different superscripts in the same column, ${ }^{\mathrm{p}, \mathrm{q}, \mathrm{r}, \mathrm{s}}$ different superscripts on the same line. 


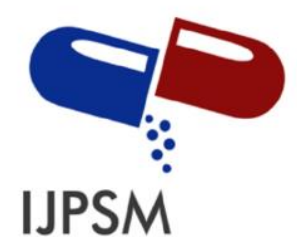

Miming Andika et al, International Journal of Pharmaceutical Sciences and Medicine (IJPSM), Vol.7 Issue. 2, February- 2022, pg. 1-6

ISSN: 2519-9889

Impact Factor: 5.721

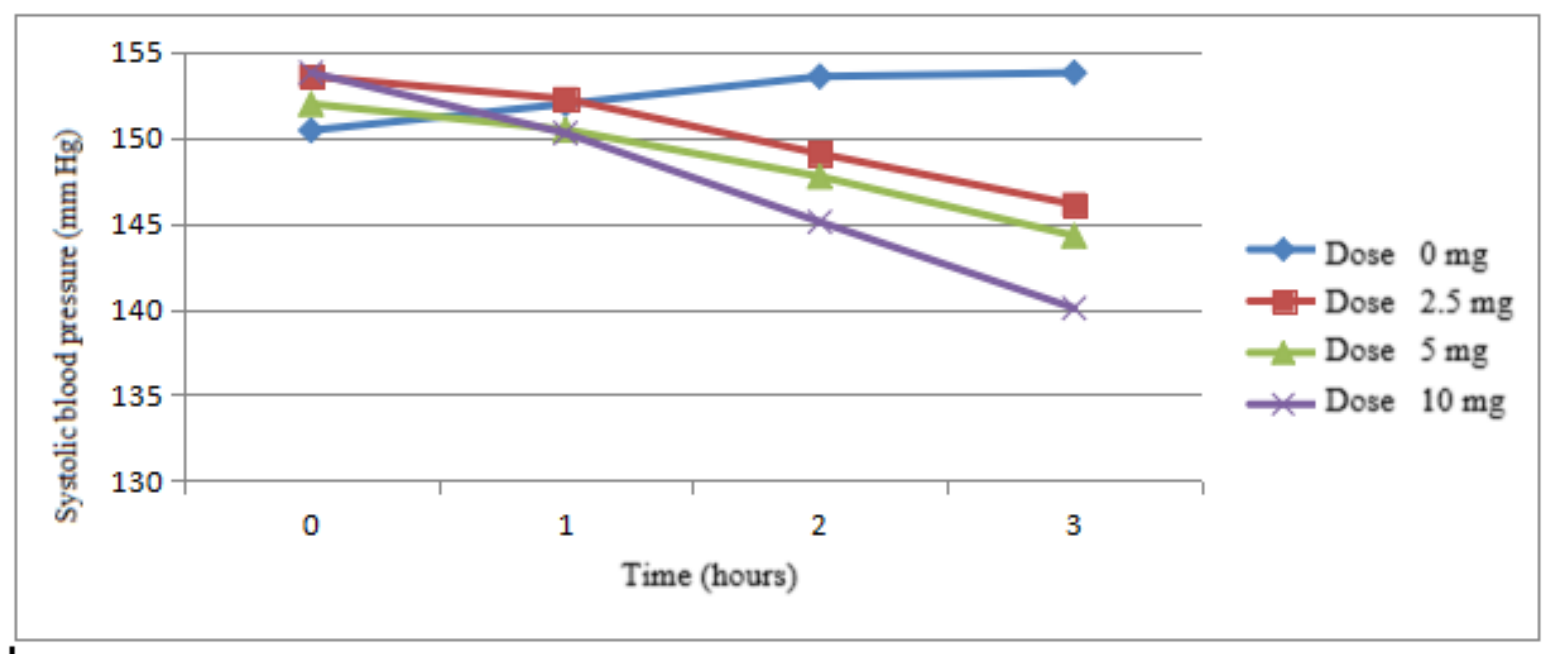

Figure 2. Graph of average systolic blood pressure in the condition of hypertension-liver dysfunction at 0,1 ,

2 , and 3 hours

The results showed that there were variations in blood pressure from each group of animals with different disease complications. The differences that arise are a matter of course. Because according to Huh, et al., 2015, his research also mentions that the incidence of hypertension increases gradually with damage to the liver. And a dose of $10 \mathrm{mg}$ is the most effective in lowering systolic blood pressure in the state of hypertension and hypertension complications with liver dysfunction ${ }^{[15]}$.

The results showed that there were variations in blood pressure from each group of animals with different disease complications. According to research conducted by Huh, et al in 2015, stated that the incidence of hypertension increases gradually with the presence of damage to the liver. And a dose of $10 \mathrm{mg}$ is the most effective in lowering systolic blood pressure in the state of hypertension and hypertension complications with liver dysfunction.

\section{Conclusion}

This study concluded that there was a significant decrease in systolic blood pressure at a dose of $10 \mathrm{mg}$ bisoprolol to decreased systolic blood pressure in hypertensive and hypertensive male white rats with complications of liver dysfunction.

\section{References}

1. Chobanian, A. V., \& Roccella, E. J. (2003). The JNC 7 hypertension guidelines. Jama, 290(10), 1312-1312.

2. Sawicka. 2011. Hypertension-The Silent Killer. Journal of Pre-Clinical and Clinical Research, 5 (2), $43-46$.

3. Mescher AL.2011. Histologi Dasar Junquiera: Text \& Atlas (12 ${ }^{\text {th }}$ edition). Jakarta, Indonesia: EGC.

4. Chobanian, A. V., Bakris, G. L., Black, H. R., Cushman, W. C., Green, L. A., Izzo Jr, J. L., ... \& National High Blood Pressure Education Program Coordinating Committee. (2003). Seventh report of the joint national committee on prevention, detection, evaluation, and treatment of high blood pressure. hypertension, 42(6), 12061252.

5. Randall, M. D \& K. E. Neil. 2009. Disease Management: A guide to clinical pharmacology. Cambridge: Cambridge University Press.

6. Aaronson, I. P., \& Ward, P. T. Jeremy., 2010. At a Glance Cardiovascular System. Edisi ke-3, Jakarta: Erlangga, hal, 100-103. 


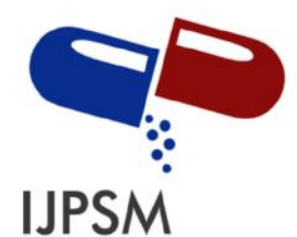

Miming Andika et al, International Journal of Pharmaceutical Sciences and Medicine (IJPSM), Vol.7 Issue. 2, February- 2022, pg. 1-6

ISSN: 2519-9889

Impact Factor: 5.721

7. Zhou, W. J., Wang, R. Y., Li, Y., Chen, D. R., Chen, E. Z., Zhu, D. L., Gao, P. J. 2013. A Randomized Controlled Study on the Effects of Bisoprolol and Atenolol on Sympathetic Nervous Activity and Central Aortic Pressure in Patients with Essential Hypertension. Journal. pone, 8 (9).

8. Taniguchi T, Ohtani T, Mizote I, Kanzaki M, Ichibori Y, Minamiguchi H, Asano Y, Sakata Y, Komuro I. 2013. Switching from carvedilol to bisoprolol ameliorates adverse effects in heart failure patients with dizziness or hypotension. J Cardio, 61(6), 417-22.

9. Eguchi, K., Hoshide, S., Kario K. 2015. Effects of Celiprolol and Bisoprolol on Blood Pressure, Vascular Stiffness, and Baroreflex Sensitivity. American Journal of Hypertension, 28 (7), 858-867.

10. Stoschitzky. K, G. Koshucharova, R. Zweiker, P. Lercher, R. Maier, N. Watzinger, W. Kraxner, W. Klein, J. Donnerer. 2003. Different effects of propranolol, bisoprolol, carvedilol and doxazosin on heart rate, blood pressure, and plasma concentrations of epinephrine and norepinephrine. J Clin basic cardiol, 6 (1-4), 69-72.

11. Vogel, H. G. (Ed.). (2002). Drug discovery and evaluation: pharmacological assays. Springer Science \& Business Media.

12. Saidu Y, Bilbis LS, Muhammad SA, Nasir MA. Serum Lipid Profile and Antioxidant Status of Salt-induced Hypertensive Rats Treated with an Antioxidants Rich Nutraceutical. Cameroon Journal of Experimental Biology. $2012 \mathrm{Jul}$ 2;8(1):47-54.

13. Soni, B., Visavadiya, N. P., \& Madamwar, D. (2008). Ameliorative action of cyanobacterial phycoerythrin on CCl4-induced toxicity in rats. Toxicology, 248(1), 59-65.

14. Abdel-Raheem IT, Abdel-Ghany AA, Mohamed GA. Protective effect of quercetin against gentamicin-induced nephrotoxicity in rats. Biological and Pharmaceutical Bulletin. 2009 Jan 1;32(1):61-7.

15. Huh, J. H., Ahn, S. V., Koh, S. B., Choi, E., Kim, J. Y., Sung, K. C., ... \& Park, J. B. (2015). A prospective study of the fatty liver index and incident hypertension: the KoGES-ARIRANG study. PLoS One, 10(11), e0143560.

\section{A Brief Author Biography}

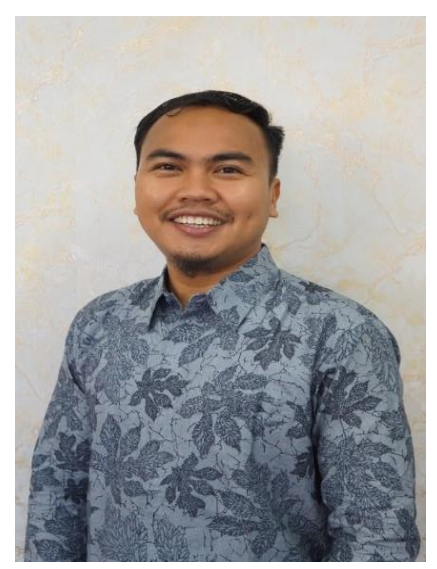

Miming Andika, M. Farm was born in Pulau Baru, Ipuh 12 Okt 1995. His father is M. Guntur, and his mother is Rahmani the author obtained a Bachelor of Pharmacy from the Department of Pharmacy, Sekolah Tinggi Ilmu Farmasi Padang (2017). Master Of Science Degree from Andalas University concentration in pharmacology (2020).

Now the Author is the Chair of the Department of Pharmacy, Faculty of Health, Fort De Kock University, Bukittinggi, West Sumatera. The author has written articles in various international journals in various science fields, such as chemistry, pharmacology, and pharmacy. 